ORIGINAL ARTICLE

\title{
Are older drivers actually at higher risk of involvement in collisions resulting in deaths or non-fatal injuries among their passengers and other road users?
}

\author{
E R Braver, R E Trempel
}

Injury Prevention 2004;10:27-32. doi: 10.1136/ip.2003.002923

\begin{abstract}
Objectives: With more older drivers on the road, public concern has been expressed about their impact on traffic safety. This study revisited the question of driver age in relation to the risks of older drivers and others sharing the road with them, including pedestrians, passengers in the same vehicle, and occupants of other vehicles.

Methods: Using United States federal data on fatal and non-fatal crashes, injury rates per driver were calculated for different types of road users. In addition, using data supplied by nine insurers, insurance claims per insured vehicle year were examined by driver age. The reference drivers were aged 30-59. Results: For fatal crashes, older drivers' major impact on road users other than themselves was an increase in death rates among their passengers, who also tended to be elderly and thus more vulnerable to injuries (rate ratio (RR) for drivers aged $75+2.52 ; 95 \%$ confidence interval (Cl) 2.39 to 2.66 ). For non-fatal crashes, drivers aged 75+ had a RR of $1.10(95 \% \mathrm{Cl} 0.98$ to 1.24$)$ for involvement in collisions resulting in injuries to other passenger vehicles' occupants compared with 30-59 year old drivers. The oldest drivers (aged 85+) had significant increases in insurance claims for injuries to other road users in crashes in which they were deemed at fault (RR 1.8; $95 \% \mathrm{Cl} 1.71$ to 1.89 ).

Conclusions: These findings suggest that the oldest drivers, a group with low average annual mileage, do pose some increased risks to occupants of other vehicles, and pose the most serious risks to themselves and their passengers.
\end{abstract}

See end of article for authors' affiliations

.....................

Correspondence to: Dr Elisa Braver, Insurance Institute for Highway Safety, $1005 \mathrm{~N}$ Glebe Road, Arlington, VA 22201,USA; research@ iihs.org or ebraver@ iihs.org
A s the population in the United States aged 65 and older increases, public concern has been expressed about the effects of this demographic shift on traffic safety. ${ }^{1}$ Drivers 65 and older are expected to be one fifth of all drivers by $2030 .^{2}$ The prevalence of medical impairments, including cognitive deficits, rises with age, along with decreased strength of bones and internal organs, ${ }^{34}$ which may increase both susceptibility to injury in crashes and driving errors that lead to crashes. ${ }^{5-14}$

Much of the concern regarding older drivers is about potential dangers to persons sharing the roads with them, particularly after well publicized crashes involving an older driver reported as at fault. ${ }^{15}$ This has led some states to require road tests or more frequent license renewals upon reaching a certain age, as well as research to determine valid methods to identify hazardous older drivers. ${ }^{16}{ }^{17}$

Whether older drivers constitute a substantial hazard to other road users besides themselves is unclear. On average, older drivers drive fewer miles annually, which lessens the risk of crash involvement per driver, ${ }^{2}{ }^{18}$ although they do have marked increases in fatal involvements per mile. ${ }^{219}$ Research suggests that frailty is the overriding factor resulting in increased older driver deaths per mile; excessive crash involvement, which affects other road users, plays a lesser part and becomes apparent by age $75 .{ }^{19}$

In two-vehicle collisions in Wisconsin involving drivers 75 and older, Dulisse reported a modestly increased risk of both deaths and hospitalizations per mile among other vehicle occupants. ${ }^{20}$ Dellinger et al also reported excess risks per mile to other road users from older drivers. ${ }^{21}$

Evans reported that older drivers were involved in few pedestrian deaths, with lower pedestrian deaths per licensed driver than young and middle aged drivers, but higher pedestrian deaths per unit of travel for the oldest drivers. ${ }^{22}$
Citing the lower quantities of travel among older drivers, Evans concluded: "Granting a license for another year to an 80 -year-old driver poses substantially less threat to other road users than granting a license to a 40 -year-old driver".

Williams and Shabanova reported that drivers 75 and older were considered at fault by police for about $70 \%-80 \%$ of deaths in two-vehicle crashes. ${ }^{23}$ A lower percentage $(36 \%-$ $43 \%$ ) of drivers aged 30-69 were deemed at fault for deaths in such crashes. Older drivers primarily were at fault for deaths among the drivers themselves and, to a lesser extent, deaths among their passengers. Older drivers were considered at fault for deaths among other vehicle occupants less often than drivers younger than 60 .

The purpose of this study was to revisit the question of driver age in relation to risks of drivers and others sharing the road with them, including pedestrians, passengers in the same vehicle, and occupants of other passenger vehicles. Unlike most previous studies, crashes resulting in non-fatal injuries and insurance injury claim data were examined in addition to fatalities. Exploring the effect of older drivers on themselves and other road users provides a more complete understanding of traffic safety risks associated with aging.

\section{METHODS}

\section{Data sources}

Multiple databases were used to study the risk per passenger vehicle driver by driver age for four categories of road users: drivers, their passengers, occupants of other passenger

\footnotetext{
Abbreviations: $\mathrm{Cl}$, confidence interval; FARS, Fatality Analysis Reporting System; GES, General Estimates System; NPTS, Nationwide Personal Transportation Survey; RR, rate ratio
} 
vehicles colliding with them in two-vehicle crashes, and nonoccupants in one-automobile crashes, including pedestrians, bicyclists, and motorcyclists.

\section{Drivers}

Active drivers by driver age, with the exception of ages 30-34, were estimated using the 1995 Nationwide Personal Transportation Survey (NPTS).$^{18}$ NPTS data from telephone interviews of a national sample of United States residents (97 881 persons in 1995) were used because standard federal licensure data include drivers dying before scheduled license renewals and license holders who no longer drive. ${ }^{24}$ Thus, standard data overstate the number of older persons who drive, which results in underestimates of crash rates. For ages 30-34, standard federal data were used because the NPTS estimate for this age group was $11.5 \%$ higher-about the same as the census estimate. Compared with federal licensure statistics, NPTS estimated about 29\% fewer drivers aged 80 and older, which likely is more accurate than standard data. For other age groups, the two databases yielded similar estimates of drivers.

To estimate active drivers during 1993-97, NPTS 1995 driver estimates were multiplied by five. This procedure appeared reasonable because licensed drivers among the different age groups increased linearly during 1993-97; also, the licensed driver counts for 1993-97 resembled the 1995 NPTS counts multiplied by five, except for ages $80+$ and $30-34 .^{24}$

\section{Deaths}

The Fatality Analysis Reporting System (FARS), the information source for motor vehicle related deaths during 1993-97, is a census of fatal crashes in the United States occurring on public roads in which a death takes place within 30 days of the crash. ${ }^{25}$

\section{Non-fatal injuries}

The General Estimates System (GES), the information source for non-fatal motor vehicle injuries during 1993-97, is a national sample of police reported crashes. ${ }^{26}$ The 55000 annual crashes in the GES are weighted according to their probability of selection so as to provide national crash estimates. The GES translates police judgments of injury severity to the $\mathrm{KABCO}$ scale $(\mathrm{K}=$ killed, $\mathrm{A}=$ incapacitating injury, $\mathrm{B}=$ visible but non-incapacitating injury, $\mathrm{C}=$ complaint of pain, $\mathrm{O}=$ no injury). This study analyzed both $\mathrm{A}$ and $\mathrm{B}$ injuries.

\section{Insurance claims}

Insurance databases provide a comprehensive picture of the most common types of crashes because police are not notified of many crashes reported to insurers, and police reported crashes are more likely to involve severe injury. Also, data on driver fault are more directly addressed than for involvements in police reported crashes. Another advantage of using insurance data was that the claims experience for ages 75-79, 80-84, and 85 and older could be computed separately rather than combining them in a single age category because, unlike FARS, GES, and NPTS, there were sufficient numbers of insured drivers in these groups to permit stable claim rate estimates.

Insurance claims by driver age-primarily non-fatal crashes-were supplied by nine insurers for vehicles three years old or newer: model years 1999-2001 during calendar years 1998-2001. The actual ages of drivers in crashes resulting in insurance claims were unknown; rather, the ages of drivers listed for those vehicles in insurance recordsreferred to as rated drivers-were analyzed. The rated driver usually is the main driver for that vehicle, but some insurers assign the highest risk driver in a household to its most valuable vehicle. This may have led to some misclassification of crashes by driver age, but likely had little effect on older drivers, who usually share a household only with other older people.

For injury claims, this study included only those made for medical expenses under bodily injury liability policies. Bodily injury liability claims are made by persons injured by a driver deemed at fault and typically are occupants of other passenger vehicles or non-occupants struck by the insured vehicle. Bodily injury liability claims, which are the strongest indicator of responsibility for other road users' injuries, were studied in all states and the District of Columbia.

Property damage liability claims, which cover property damage to other vehicles caused by insured drivers, also were analyzed in all 50 states and the District of Columbia. Property damage liability claims, which are filed more often than injury claims, are not necessarily associated with injuries, but are another indicator of the crash patterns of drivers in different age groups.

\section{Analytic methods}

The magnitude of the public health problem of motor vehicle injuries by driver age is shown by absolute numbers of vehicle related deaths and non-fatal injuries. Risks per driver or per insured vehicle are another measure of impact on the population exposed to vehicle travel.

Rate ratios (RR) and their 95\% confidence intervals (CI) were calculated to quantify differences among driver age groups with regard to deaths per driver, persons with nonfatal injuries (incapacitating and visible non-incapacitating) per driver, and claims per insured vehicle year. Ages 30-59 were used as a reference group to facilitate comparisons among younger, older, and middle range drivers. Analyses were done using SAS, Microsoft Excel, and SUDAAN. ${ }^{27-29}$

\section{RESULTS \\ Deaths}

Young drivers

Table 1 presents deaths during 1993-97 and NPTS estimates of active drivers by driver age. The greatest numbers of deaths arose from collisions involving teenage drivers and drivers aged 20-29. Per driver younger than 30-especially those under 25-raised RRs of death were observed among all road user types compared with drivers aged 30-59. Deaths among non-occupants and other vehicle occupants frequently occurred in collisions with younger drivers. A striking finding was a RR of 5.79 (95\% CI 5.50 to 6.09) for passenger deaths in vehicles of teenage drivers. Passenger deaths per driver also were significantly raised among drivers in their 20 s.

\section{Older drivers}

Among drivers 75 and older, significantly raised RRs were observed only for driver deaths (RR 3.02; $95 \%$ CI 2.86 to 3.19 ) and passenger deaths (RR 2.52; 95\% CI 2.39 to 2.66) relative to ages 30-59 (table 1; fig 1). Smaller elevations were observed among drivers aged 70-74 (RR for driver deaths 1.35; RR for passenger deaths 1.31). The absolute number of passenger deaths associated with the oldest drivers was far lower than passenger deaths for young drivers.

Most passengers of older drivers were elderly. In both police reported towaway and fatal crashes during 1993-97, about $75 \%$ of passengers transported by drivers aged 75 and older were 70 and older. ${ }^{25} 30$

Among drivers aged 60-74, risks of death among occupants of other passenger vehicles and non-occupants were significantly lower compared with ages 30-59. When drivers reached age 75 , there was an upturn in fatality risk among 


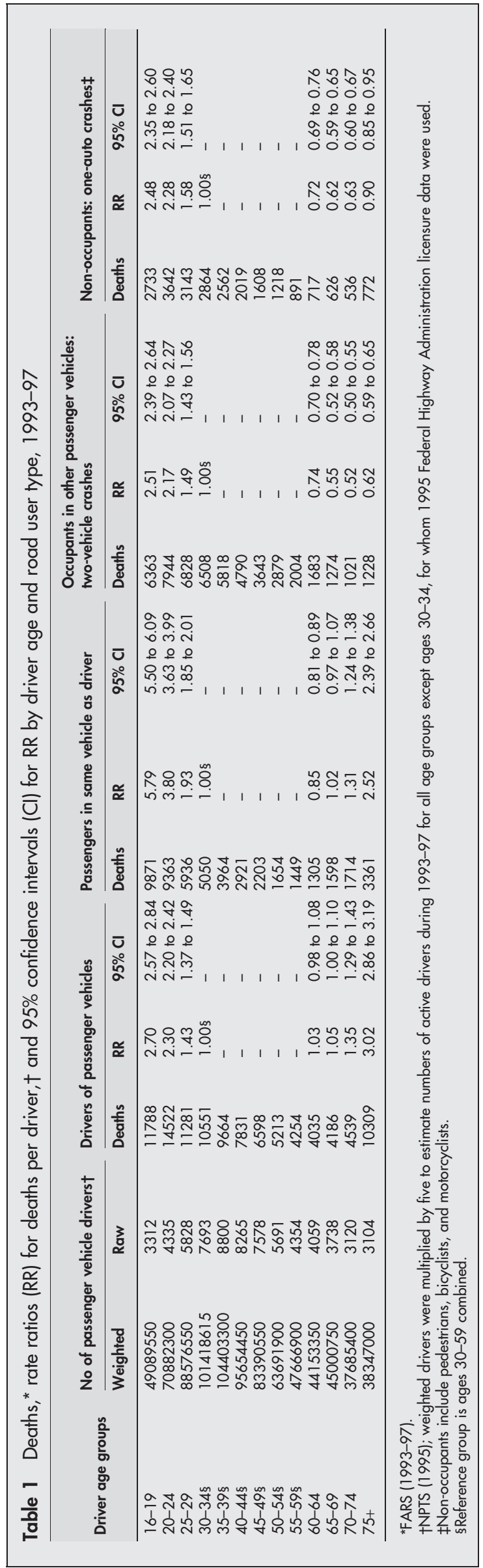

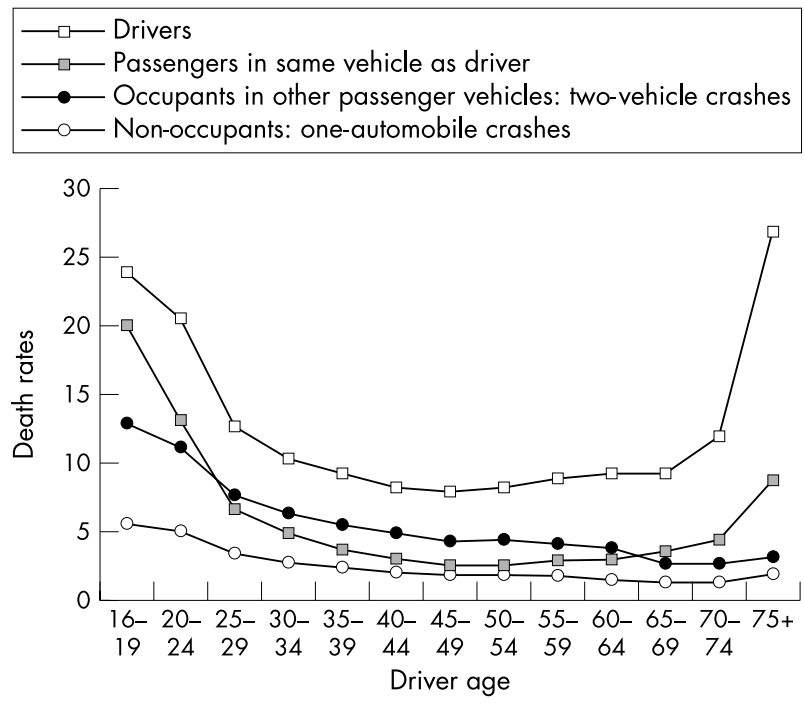

Figure 1 Deaths per 100000 drivers by driver age and person type, 1993-97 FARS and 1995 NPTS.

these types of road users, but their RRs relative to 30-59 year old drivers remained below 1.0.

Two thirds of the deaths in crashes involving drivers 75 and older were the drivers themselves. Drivers younger than 60 comprised fewer than $50 \%$ of motor vehicle deaths in their collisions.

\section{Non-fatal injuries}

General Estimates System

Persons with non-fatal injuries described by police as incapacitating or visible but non-incapacitating were studied. RRs for the two injury severities were similar so they were combined (table 2; fig 2).

\section{Young drivers}

Younger drivers had much higher involvement rates in crashes resulting in non-fatal injuries to themselves than 30-59 year old drivers. As was true for fatalities, teenage drivers posed a greater risk of non-fatal injury to their passengers, non-occupants, and occupants in other vehicles than drivers in any other age group. The fatal and non-fatal injury rates per driver of passengers of teenage drivers both were more than five times as high as those of 30-59 year old drivers. For both fatal and non-fatal crashes, drivers in their 20s had lower risks than teenage drivers but their risks still were raised.

\section{Older drivers}

The pattern for non-fatal injuries was for drivers aged 60-74 to have RRs for injuries well below 1.0 compared with ages 30-59, but for drivers 75 and older to have modest upturns in risk that were not as high as those for teenage drivers.

With some exceptions, results for non-fatal injuries among older drivers had patterns resembling those for deaths. One difference was that RRs for non-fatal injuries among older drivers and their passengers ( 1.16 and 0.86 , respectively) were far lower than those for deaths (3.0 and 2.5, respectively).

Another difference is that although older drivers had lower rates of collisions resulting in occupant deaths in other passenger vehicles, drivers 75 and older had a $10 \%$ increase (statistically non-significant) compared with ages 30-59, in two-vehicle crash involvements resulting in non-fatal injuries to other vehicle occupants (RR 1.10; 95\% CI 0.98 to 1.24 ). 

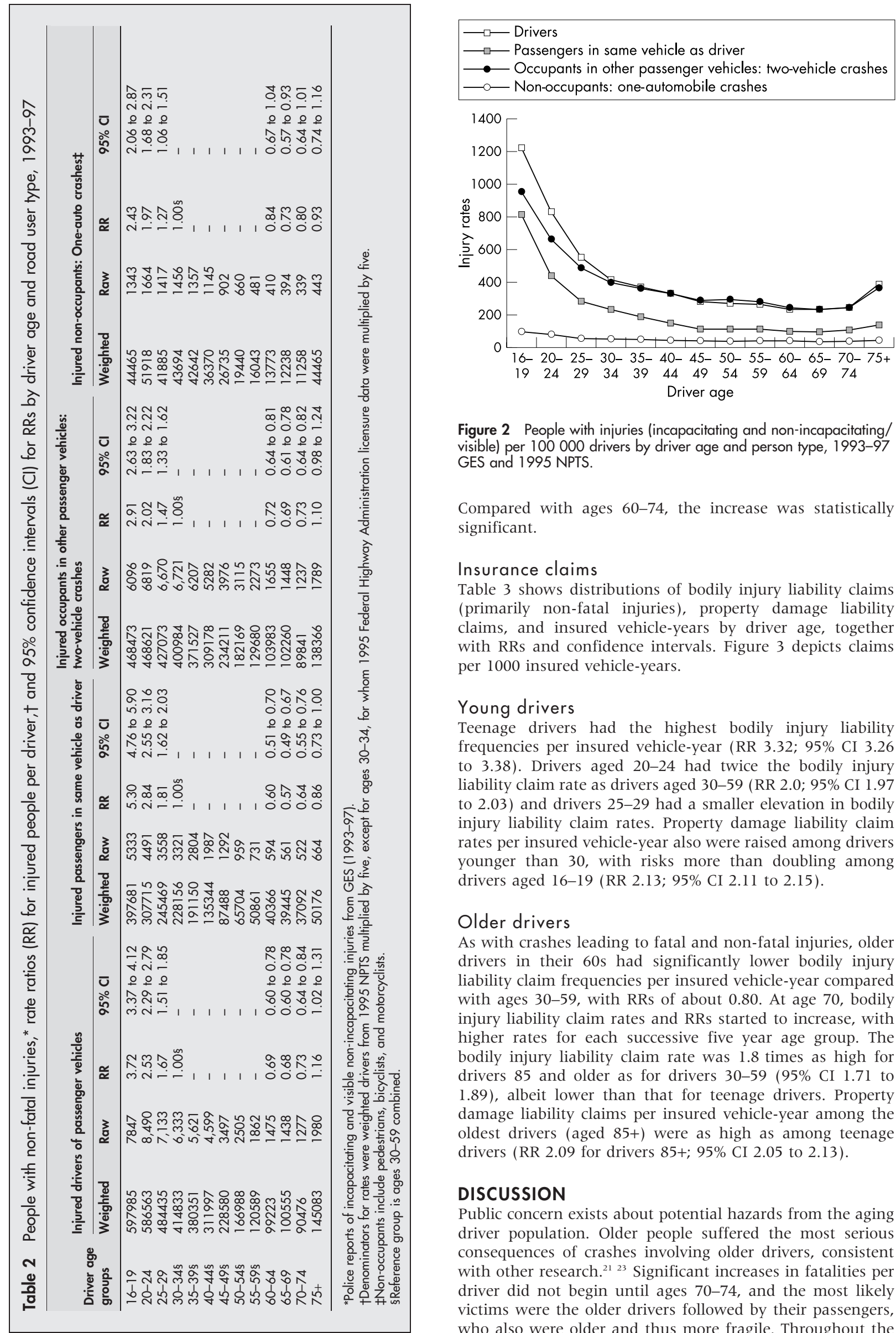

Figure 2 People with injuries (incapacitating and non-incapacitating/ visible) per 100000 drivers by driver age and person type, 1993-97 GES and 1995 NPTS.

Compared with ages $60-74$, the increase was statistically significant.

\section{Insurance claims}

Table 3 shows distributions of bodily injury liability claims (primarily non-fatal injuries), property damage liability claims, and insured vehicle-years by driver age, together with RRs and confidence intervals. Figure 3 depicts claims per 1000 insured vehicle-years.

\section{Young drivers}

Teenage drivers had the highest bodily injury liability frequencies per insured vehicle-year (RR 3.32; 95\% CI 3.26 to 3.38). Drivers aged 20-24 had twice the bodily injury liability claim rate as drivers aged 30-59 (RR 2.0; 95\% CI 1.97 to 2.03) and drivers 25-29 had a smaller elevation in bodily injury liability claim rates. Property damage liability claim rates per insured vehicle-year also were raised among drivers younger than 30, with risks more than doubling among drivers aged 16-19 (RR 2.13; 95\% CI 2.11 to 2.15).

\section{Older drivers}

As with crashes leading to fatal and non-fatal injuries, older drivers in their 60s had significantly lower bodily injury liability claim frequencies per insured vehicle-year compared with ages 30-59, with RRs of about 0.80 . At age 70, bodily injury liability claim rates and RRs started to increase, with higher rates for each successive five year age group. The bodily injury liability claim rate was 1.8 times as high for drivers 85 and older as for drivers 30-59 (95\% CI 1.71 to 1.89), albeit lower than that for teenage drivers. Property damage liability claims per insured vehicle-year among the oldest drivers (aged 85+) were as high as among teenage drivers (RR 2.09 for drivers 85+; 95\% CI 2.05 to 2.13 ).

\section{DISCUSSION}

Public concern exists about potential hazards from the aging driver population. Older people suffered the most serious consequences of crashes involving older drivers, consistent with other research. ${ }^{21}{ }^{23}$ Significant increases in fatalities per driver did not begin until ages 70-74, and the most likely victims were the older drivers followed by their passengers, who also were older and thus more fragile. Throughout the 
Table 3 Insurance claims, ${ }^{*}$ rate ratios (RR) for claims per insured vehicle-year, and $95 \%$ confidence intervals (CI) by driver age and type of claim, model years 1999-2001

\begin{tabular}{|c|c|c|c|c|c|c|c|c|}
\hline \multirow[b]{2}{*}{$\begin{array}{l}\text { Driver age } \\
\text { groupst }\end{array}$} & \multicolumn{4}{|c|}{ Bodily injury liability claims } & \multicolumn{4}{|c|}{ Property damage liability claims } \\
\hline & Insured vehicle-years & Claims & RR & $95 \% \mathrm{Cl}$ & $\begin{array}{l}\text { Insured vehicle- } \\
\text { years }\end{array}$ & Claims & RR & $95 \% \mathrm{Cl}$ \\
\hline $16-19$ & 602994 & 15358 & 3.32 & 3.26 to 3.38 & 746646 & 54886 & 2.13 & 2.11 to 2.15 \\
\hline $20-24$ & 1917585 & 29428 & 2.00 & 1.97 to 2.03 & 2403555 & 135489 & 1.64 & 1.63 to 1.65 \\
\hline $25-29$ & 2606488 & 25346 & 1.27 & 1.25 to 1.29 & 3338590 & 135356 & 1.18 & 1.17 to 1.19 \\
\hline $30-59 \ddagger$ & 16716602 & 128185 & $1.0 \ddagger$ & - & 21644388 & 745969 & $1.0 \ddagger$ & - \\
\hline $60-64$ & 1479610 & 9084 & 0.80 & 0.78 to 0.82 & 1845684 & 56425 & 0.89 & 0.88 to 0.90 \\
\hline $65-69$ & 1146822 & 7205 & 0.82 & 0.80 to 0.84 & 1416686 & 44898 & 0.92 & 0.91 to 0.93 \\
\hline 70-74 & 911061 & 6788 & 0.97 & 0.95 to 0.99 & 1103764 & 40290 & 1.06 & 1.05 to 1.07 \\
\hline 75-79 & 648005 & 5938 & 1.20 & 1.17 to 1.23 & 761288 & 34080 & 1.30 & 1.29 to 1.31 \\
\hline 80-84 & 317667 & 3519 & 1.44 & 1.39 to 1.49 & 362758 & 20483 & 1.64 & 1.62 to 1.66 \\
\hline $85+$ & 109891 & 1515 & 1.80 & 1.71 to 1.89 & 124304 & 8964 & 2.09 & 2.05 to 2.13 \\
\hline
\end{tabular}

older ages, there were low rates of crashes fatal to other road users, including other vehicle occupants, after declining greatly from high levels per driver among teenagers and 20-29 year olds.

Analyses of non-fatal injuries and insurance claims showed that other road users did experience some of the injury burden and property losses associated with older drivers. This study differed from past studies, which observed increased risk to other road users per mile, but generally not increased risks per driver. ${ }^{20-22}$ Although older drivers did not pose an excess risk of non-fatal injury to passengers of their vehicles or to non-occupants, risks to occupants of other passenger vehicles (and to the drivers themselves) did increase when drivers reached age 75 . The effect of older drivers' crashes on other road users was most evident for insurance liability claims, suggesting increased at-fault crashes. Relative to ages 30-59, bodily injury liability claims nearly doubled at ages 85 and older, and, after a low point at ages 60-69, property damage liability claims increased with age so that the claim rate against drivers 85 and older doubled.

To put this into perspective, it is important to recognize that younger drivers, both teenagers and people in their 20s, represent a substantially greater public health problem than older drivers for both fatal and non-fatal motor vehicle injuries. With the exception of driver death rates among drivers 75 and older, teenage drivers posed the highest risks of death and non-fatal injury to themselves, their passengers, occupants of other passenger vehicles, and non-occupants.

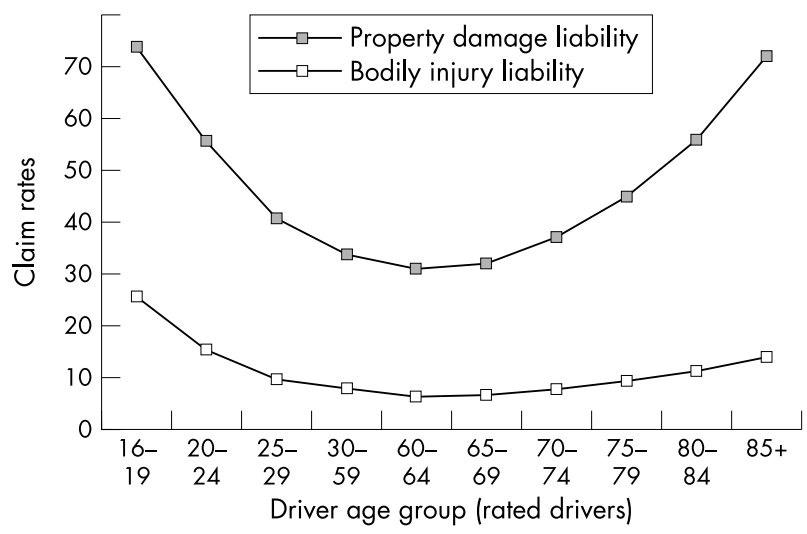

Figure 3 Claims per 1000 insured vehicle-years by rated driver age and type of claim, model years 1999-2001.
Risks declined among drivers in their 20s, but were significantly greater compared with 30-59 year olds.

Property damage liability claims per insured vehicle year were similar among the youngest and oldest drivers, but teenage drivers had much higher bodily injury liability claim rates. This suggests that the oldest drivers have a comparable risk of involvement in at-fault crashes, but are less likely than younger drivers to injure others.

Why older drivers were associated with an increased risk of bodily injury liability claims, property damage liability claims, and non-fatal injuries, but not fatal injuries, to occupants of other passenger vehicles is unknown. The travel patterns of older drivers, who travel less at night and more on roads with speed limits below $55 \mathrm{mph}$, may reduce fatality risk. ${ }^{31}$

One important point when interpreting the current study is that injuries described as incapacitating or visible nonincapacitating by police typically are minor. ${ }^{32}$ A limitation of insurance databases is that they are confined to newer vehicles (1-3 years old), which might have higher annual mileage and healthier older drivers with more resources than is typical. Another limitation is that confounding factors such as travel speeds and alcohol impairment could not be studied.

Screening to identify older drivers at very high risk of crashing might protect both older drivers and other road users, but consensus has not been reached on feasible and

\section{Key points}

- With the exception of deaths among their passengers, many of whom were older than 70 and thus more fragile, older drivers were not overinvolved in crashes in which other road users were killed.

- Drivers aged 75+ appeared at modestly increased risk of involvement in two-vehicle collisions in which occupants of other vehicles received non-fatal injuries.

- Drivers aged $85+$ had an $80 \%$ increase in bodily injury liability claims per insured vehicle-year relative to $30-$ 59 year-old drivers.

- Drivers in their teens and 20 s posed the greatest risk to their passengers and other road users.

- Older drivers experienced the most serious consequences of their collisions: two thirds of the deaths in crashes involving drivers 75 and older were the drivers themselves. 
valid methods to detect unsafe drivers and avoid falsely characterizing safe drivers as hazardous. ${ }^{17}$ Research on driver screening should continue, because screening might provide useful information to drivers and physicians when considering whether modifications in driving might be appropriate for individuals. Efforts to enhance the protection afforded to older vehicle occupants, such as improving restraint systems and vehicles, should be vigorously pursued because older people are more susceptible to injury and will continue to travel in vehicles whether or not they are driving. ${ }^{1933}$

\section{ACKNOWLEDGEMENTS}

The authors would like to thank Sergey Y Kyrychenko of the Insurance Institute for Highway Safety for statistical advice. This work was supported by the Insurance Institute for Highway Safety and Highway Loss Data Institute.

\section{Authors' affiliations}

E R Braver, Insurance Institute for Highway Safety, Arlington, Virginia

R E Trempel, Highway Loss Data Institute, Arlington, Virginia

\section{REFERENCES}

1 American Medical Association. AMA addresses older driver safety. Chicago, IL, 2002 Available at: http://www.ama-assn.org/ama/pub/article/24036552.html (accessed on 29 September 2002).

2 Lyman S, Ferguson SA, Braver ER, et al. Older driver involvements in police reported crashes and fatal crashes: trends and projections. Inj Prev 2002;8: 11 6-20.

3 Augenstein J. Differences in clinical response between the young and elderly. Aging and Driving Symposium, Southfield, MI. Des Plaines, IL: Association for the Advancement of Automotive Medicine, February, 2001:19-20.

4 Skoog I, Nilsson L, Palmertz B, et al. A population-based study of dementia in 85-year-olds. N Engl J Med 1993;328:153-8.

5 Barancik JI, Chatterjee BF, Greene-Cradden YC, et al. Motor vehicle trauma in northeastern Ohio; I: incidence and outcome by age, sex, and road-use category. Am J Epidemiol 1986;123:846-61.

6 Evans L. Older driver involvement in fatal and severe traffic crashes. J Gerontol 1988:43:S186-93.

7 Evans L, Gerrish PH. Gender and age influence on fatality risk from the same physical impact determined using two-car crashes. SAE technical paper series 2001-01-1174. Warrendale, PA: Society of Automotive Engineers, 2001.

8 Foley DJ, Wallace RB, Eberhard J. Risk factors for motor vehicle crashes among older drivers in a rural community. J Am Geriatr Soc 1995;43:776-81

9 Hall MJ, Owings MF. Hospitalizations for injury: United States, 1996. Hyattsville, MD: National Center for Health Statistics, 2000.

10 Kim K, Nitz L, Richardson J, et al. Personal and behavioral predictors of automobile crash and injury severity. Accid Anal Prev 1995;27:469-81.

11 Marottoli RA, Cooney LM, Wagner R, et al. Predictors of automobile crashes and moving violations among elderly drivers. Ann Intern Med 1994;121:842-6.
12 McGwin G Jr, Sims RV, Pulley L, et al. Relations among chronic medical conditions, medications, and automobile crashes in the elderly: a populationbased case-control study. Am J Epidemiol 2000;152:424-31.

13 Underwood $M$. The older drivers: clinical assessment and injury prevention. Arch Intern Med 1992;152:735-40.

14 Waller PF, Stewart JR, Hansen AR, et al. The potentiating effects of alcohol on driver injury. J Am Med Assoc 1986;256:1461-6.

15 National Highway Traffic Safety Administration. Addressing the safety issues related to younger and older drivers: a report to Congress on the research agenda of the National Highway Traffic Safety Administration, January 19, 1993. Washington, DC: US Department of Transportation. Available at: http://www.nhtsa.dot.gov/people/injury/olddrive/pub/yorept.html (accessed 2 October 2002).

16 Insurance Institute for Highway Safety. US driver licensing renewal procedures for older drivers. Arlington, VA: IIHS, 2002. Available at: http:// www.highwaysafety.org/safety_facts/state_laws/older_drivers.htm (accessed 19 September 2002).

17 National Highway Traffic Safety Administration. Safe mobility for older people notebook. Report No DOT HS-808-853. Washington, DC: US Department of Transportation, 1999.

18 Federal Highway Administration. 1995 Nationwide Personal Transportation Survey. Washington, DC: US Department of Transportation, 1997.

19 Li G, Braver ER, Chen L-H. Fragility versus excessive crash involvement as determinants of high death rates per vehicle-mile of travel among older drivers. Accid Anal Prev 2003;35:227-35.

20 Dulisse B. Older drivers and risk to other road users. Accid Anal Prev 1997;29:573-82.

21 Dellinger AM, Kresnow M, Sehgal M. Do older drivers impose an excess risk of death or injury on others (abstract)? Am J Epidemiol 2003;157:S71.

22 Evans L. Risks older drivers face themselves and threats they pose to other road users. Int J Epidemiol 2000;29:315-22.

23 Williams AF, Shabanova VI. Responsibility of drivers, by age and gender, for motor vehicle crash deaths. J Safety Res 2003 (in press)

24 Federal Highway Administration. Highway statistics series (1993 through 1997). Washington, DC: US Department of Transportation, 1994-98. Available at: http://www. fhwa.dot.gov/ohim/ohimstat.htm (accessed 3 October 2002).

25 National Highway Traffic Safety Administration. Fatality Analysis Reporting System, 1993-97. Washington, DC: US Department of Transportation, 1994-98.

26 National Highway Traffic Safety Administration. General Estimates System 1993-97. Washington, DC: US Department of Transportation, 1994-98.

27 Microsoft Corporation. Microsoft Excel 2000. Redmond, WA: Microsoft Corporation, 2000

28 RTI International. SUDAAN version 8. Research Triangle Park, NC: RTI International, 2001

29 SAS Institute, Inc. SAS Version 8.2. Cary, NC: SAS Institute, Inc, 2001.

30 National Highway Traffic Safety Administration. National Automotive Sampling System/Crashworthiness Data System, 1993-97. Washington, DC US Department of Transportation, 1994-98.

31 National Highway Traffic Safety Administration. National survey of speeding and other unsafe driving actions; vol. II: driver attitudes and behavior. Washington, DC: US Department of Transportation, 1998. Available at: http://www.nhtsa.dot.gov/people/injury/aggressive/unsafe/att-beh/ Chapt 1-2.html (accessed 12 July 2001).

32 Farmer CM. Reliability of police-reported information for determining crash and injury severity. Traffic Injury Prevention 2003;4:38-44.

33 Wang SC. An aging population: fragile, handle with care. Washington, DC National Highway Traffic Safety Administration, 2001. Available at: http:// www-nrd.nhtsa.dot.gov/departments/nrd-50/ciren/um_fragile.htm (accessed 27 July 2001). 